\title{
Green Chemistry: A tool to erase environmental pollution
}

\section{Narendra Kumar Chaudharya}

\section{Introduction:}

We live in a world completely grounded on chemistry. Everything that we are and do is controlled by chemistry. Environmental pollution caused by chemicals is a most challenging fact which starves nation's development and toxicates human health. Unplanned and high rate of urbanization, establishment of large number of industries and increasing number of vehicles release various pollutants. The pollutants are being added in air, in water, in our food supply and in soil. Global warming is one of the outcomes of chemical pollution that pulls attention of scientists and researchers to control it. Therefore, international community is under increasing pressure to find methods to save our lives from the increasing pollution. The scientists and concerned are searching new alternatives which do not cause environmental pollution. This new approach is called green chemistry. The principles of green chemistry focus on reducing, recycling, or eliminating the use of toxic chemicals in chemistry by finding creative ways to minimize the human and environmental impact without stifling scientific progress.

\section{What is green Chemistry?}

Green chemistry is the utilization of a set of principles that reduces or eliminates the use or generation of hazardous substances in the design, manufacture and applications of

* Teaching Assistant, Department of Chemistry, M.M
Its aim is to virtually eliminate toxic, persistent substances from the environment by ensuring their no further releases and destroying existing deposits of these chemicals.

\section{Principles of green chemistry:}

Followings are the principles of green chemistry:

(1) Chemical synthesis should be designed to prevent waste, leaving no waste to treat or
clean up.

(2) Synthetic methods should be designed to maximize the formation of products

(3) Synthetic methods should be designed to use and generate substances with little or no toxicity to humans and the
environment.

(4) Raw materials are feed stocks used to generate products, should be renewable rather than depleting.

(5) Avoid using solvents, separation agents and other auxiliary chemicals whenever possible. If a solvent is necessary, water is a good medium that do not contribute to smog formulation or destroy the ozone.

(6) Design chemical products to breakdown to harmless substances after use, so that they do not accumulate in the environment.

(7) The products should be analyzed to real time to minimize or eliminate the 
(8) Substances and their forms used in a chemical process should be chosen to minimize the potential for chemical accidents including explosion, fires and chemicals released to the environment.

(9) Synthetic method should be conducted at ambient temperatures and pressure.

(10) Synthetic method should be designed such that the final product contains the maximum proportion of starting materials.

(11) Work should be minimized by catalyzing reaction.

(12) Unnecessary derivatization (blocking or protecting groups or any temporary modifications of physical and chemical processes) should be avoided whenever possible.

\section{Role of chemists in Green chemistry:}

Green chemistry not only helps to erase environmental pollution through its principle but also leads to cost reduction of chemical products in industries.

Chemists use their creative and innovative skills to develop new processes, new synthetic methods through research. Hence there should be continuous research in this field by the chemists so that the public will consume better qualities of industrial products without any toxicity.

Chemists should work together in a spirit of humanism and tolerance to help achieve sustainable development. Principle of green chemistry should be used in scientific research and brought into industrial development.
Some Achievements of green chemistry:

(1) In 1996, Dow chemical won the 1996 Greener reaction condition award for using $\mathrm{CO}_{2}$ as the blowing agent for polystyrene foam production. This technology eliminates the use of CFC blowing agent which contribute to ozone layer depletion and global warming.

(2) In 2006, professor Galon J Supper, was awarded for his system of converting waste glycerin form biodiesel to propylene glycol which replace more toxic ethylene glycol as automobiles antifreeze.

(3) In 2009 July 28, Tijs Lammens at Wageningn University, the Netherlands and colleagues converted glutamic acid into $r$ amino butyric acid using a decarboxylase enzyme. Glutamic acid is the waste product in the conversion of maize grain into bioethanol. $y$ aminobutyric acid can be turned into many useful products in industries.

(4) Azo dyes used to color fabrics can cause cancer and pose health hazard when released into the environment in wastewater. Hong-Wen Gao and colleagues from Tongji University, Shanghai, developed a method to reuse waste dyes to color fabrics. They mixed two water samples- one containing a cationic azo dye and the other an anionic azo dye. They added sodium carbonate followed by calcium chloride and the dyes precipitated out of solution as a dye calcium carbonate hybrid. This dye can be used for coloring plastics and rubber. 


\section{Conclusion:}

Green world is the dream of researchers and concerned, related to green chemistry. Its aim to erase pollution and make world healthy through green chemistry is highly appreciable and we hope this will definitely gear up the world by eliminating hazardous substances from nature through design, manufacture and application of chemical products.

\section{References:}

1. Note on Environment, Health and committee published April 5.

by RSC, 2002

2. www.rsc.org/highlightschemtechnol, 2009

3. www.rsc.org/highlightschemtechnol, RSC 